\title{
Resource-Efficient Methods to Facilitate the Preservation of a Reservoir's Self-Cleaning Potential
}

\author{
Vitaliy V. Chelnokov', Aleksey V.Matasov¹, Elena Zabolotnaya ${ }^{1,2^{*}}$, Anna S. \\ Makarova1, and Andrey N. Glushko ${ }^{3}$ \\ ${ }^{1} \mathrm{D}$. Mendeleev University of Chemical Technology of Russia \\ 2 JSC "Fine Chemicals R\&D Centre" \\ ${ }^{3} \mathrm{SIC}$ Kurchatov Institute - IREA.
}

\begin{abstract}
The aim of this research was to develop environmental methods for the restoration and rehabilitation of Moscow's water bodies. A number of methods are recommended. These can help to improve the environmental condition and water quality of water bodiesin Moscow.

Keywords: ehabilitation of water body, engineering biology, environmental preservation
\end{abstract}

Corresponding Author:

Zabolotnaya Elena.

Email:zabolotnaya.e@inbox.ru

ORCID 0000-0002-5461-5145

\section{Dates}

Published 13 January 2022

Publishing services provided by Knowledge E

(c) Vitaliy V. Chelnokov et

al.. This article is distributed

under the terms of the Creative

Commons Attribution License,

which permits unrestricted use

and redistribution provided that

the original author and source are credited.

Selection and Peer-review under the responsibility of the 8th Scientific and Practical Conference Conference Committee.

\section{Introduction}

The choice of practical solutions for the organization of territories depends on the mode of the particular use. At the same time, regardless of the state of the water body and the adjacent territory of the natural-territorial complex, the main requirement for its rehabilitation is to meet the following conditions:

i. the maximum preservation effect of biological corridor;

ii. ecological balance support;

iii. activation of water protection functions of the coastal zone.

The main requirement for the biological corridor existence is to ensure the continuity of natural complex elements by maintaining a continuous green planting zone and connecting it with sections of the existing or restored natural complex around the water body [1]. Maximum possible level of ecosystem preservation reaches by observing two principles of biosphere organization: the diversity of animal organisms and the systematic organization of the biogenic cycle [2].

\section{S OPEN ACCESS}




\section{Methodology}

The diversity of the biosphere is ensured by restoring and maintaining all the species and groups peculiar to this territory. The following species are typical for natural inundable areas: poplar, silver maple, alder, willow, elm, grouped by typological principle with an undergrowth of honeysuckle, meadowsweet, briar, spruce and fir (mainly on the Northern and Eastern slopes). The stability of natural and artificial (recoverable) biocenoses is enhanced by increasing their biological diversity and combining all green areas into a single green framework. This is achieved by:

i. increasing of the total plant communities area; mosaics of vegetation cover;

ii.zoning of the area with the allocation of limited availability zones for the reproduction of rare and vulnerable species; restriction and protection from damaging agents of the urban environment.

All this increases the longevity of plantings due to everlasting greenery, reduces costs and reduces maintenance charges. The water-protecting role of the adjacent territories is to maintain a dense grass cover on the slopes and valley areas, creating sufficient water permeability of the soil-ground layer to detain pollution coming from the slope stream; performing a garbage-retaining role for tree and shrub vegetation; countering vegetation erosion, soil erosion and landslide events [3]. The main landscape requirement for the arrangement of inundable and coastal areas in urban conditions is the creation of landscaping in the form of a spatial structure that helps to reduce the negative impact of urbanized city environment on the water body. Requirements for recreational use of coastal territories include (except for territories with a special protection regime) regulation of recreational load. The permissible recreational load is calculated according to SNiP 2.07.01-89 people/hectare: for parks of recreation areas 70, for forest parks (meadow parks, hydroparks) - 10, for forests - 103.

\section{Conclusion}

The creation of a vegetative cover capable of self healing in areas of mass recreation use, is provided with the device road and path network, performed in accordance with the requirements of SNiP 2.07.01-89, to redistribute the flow of tourists and distract from vulnerable areas and habitats of rare species and also for functional zoning with the allocation of venues for sport, quiet recreation, places for campfires, fishing and private protected areas. Engineering preparation and arrangement of the territory before carrying out works on its greening include: execution of vertical land levelling 
in accordance with SNiP 2.07.01-89; organization of a catchment area with maximum protection from flooding, washouts and various pollutants entry in accordance with SNiP 2.04.03-85; carrying out anti-erosion, bank protection, anti-landslide measures and works; localization of sources of contamination prevalence or reclamation of disturbed land. A special requirement for the development of floodplain and coastal areas is the implementation of most of the environmental measures using engineering biology methods, which consist in the use of natural functions performed by green spaces [4].

\section{Acknowledgement}

This study was carried out in the framework of the grant RFBR № 18-29-25068.

\section{References}

[1] Balushkina EV. Application of an integral indicator for assessing water quality based on structural characteristics of bottom communities.Reaction of Lake Ecosystems to Changes in External Conditions. Saint Petersburg: Zoologicheskiy institute; 1997.

[2] Beznosov VN, Rodionov VB,Suzdaleva AA. Engineering and ecological monitoring and actual ways of ecological arrangement of small rivers.Safety of Power Structures. 2004;14:206-220.

[3] Alimov AF.Biotic relationships in the ecosystem of nursery lakes. Saint Petersburg:Hydrometeoizdat; 1993.

[4] Braginsky LP.Principles of classification and some mechanisms of structural and functional rearrangements of freshwater ecosystems in the conditions of anthropogenic press.Hydrobiological Journal. 1998;34(6):72-94. 